\title{
QUEM É ESTUDANTE FALANTE DE PORTUGUÊS EM FAMÍLIAS DE ORIGEM BRASILEIRA EM TORONTO, CANADÁ? QUESTÕES DE CLASSE
}

\author{
Pedro de Moraes Garcez ${ }^{*}$ \\ Universidade Federal do Rio Grande do Sul \\ Instituto de Letras \\ Departamento de Linguística, Filologia e Teoria Literária \\ Porto Alegre, RS, Brasil
}

\begin{abstract}
Resumo: Filhos de famílias de migrantes de origem brasileira em Toronto podem ser vistos como estudantes falantes de português, expressão usada por direções escolares da cidade para identificar luso-canadenses marcados por insucesso escolar. Entrevistas com estudantes de origem brasileira que frequentavam escolas de uma mesma Direção Escolar e suas famílias mostram, porém, perfis socioeconômicos distintos, conforme indicado pelas regiões de residência e as ocupações dos pais, associados a ideologias de linguagem diferentes. Amostras do discurso de entrevistados em cada perfil sobre o valor de falar português revelam indícios de aproximação apenas dos migrantes brasileiros com menos qualificação profissional à etnoclasse falante de português luso-canadense. O distanciamento do português por parte de uma estudante nesse perfil que, entretanto, possui aspirações acadêmicas aprofunda o entendimento das diferentes perspectivas do que é ser estudante falante de português em Toronto. O estudo reforça a relevância de classe social para os estudos da linguagem na contemporaneidade.
\end{abstract}

Palavras-chave: Classe social. Globalização. Ideologias de linguagem. Migração. Mobilidade.

\section{FALANTES DE PORTUGUÊS EM TORONTO E A CATEGORIA "ESTUDANTE FALANTE DE PORTUGUÊS" ("PORTUGUESE-SPEAKING STUDENT”) NOS DISCURSOS ESCOLARES NA CIDADE}

Toronto tem sido destino importante para emigrantes de Portugal desde a década de 1950 (TEIXEIRA; MURDIE, 2009) e, mais recentemente, para migrantes brasileiros (BRASCH, 2007; MAGALHÃES et al., 2009). Há estimativas de mais de 500.000 falantes de português entre a população canadense (TEIXEIRA; ROSA, 2009, p. 7; SILVA, 2013, p. 174), a maior parte concentrados em Toronto e arredores. No Censo do Canadá de 2011, quase 226.000 pessoas declararam o português como língua primária (STATISTICS CANADA, 2012, p. 4), número que aumentou conforme informações preliminares do Censo do Canadá de 2016 (Tabela 1).

\footnotetext{
* PhD em Educação, Cultura e Sociedade pela University of Pennsylvania, Estados Unidos. Professor Titular. ORCID: https://orcid.org/0000-0001-8642-678X. E-mail: pedrom.garcez@ufrgs.br.
}

GARCEZ, Pedro de Moraes. Quem é estudante falante de português em famílias de origem brasileira em Toronto, Canadá? questões de classe. Linguagem em (Dis)curso - LemD, Tubarão, SC, v. 18, n. 3, p. 729-749, set./dez. 2018. 
Tabela 1 - Falantes de português e pessoas nascidas no Brasil e em Portugal conforme os Censos do Canadá de 2011 e 2016

\begin{tabular}{|l|l|r|r|}
\hline Ano & Português como língua primária & Nascidos no Brasil & Nascidos em Portugal \\
\hline \multirow{2}{*}{2011} & \multirow{2}{*}{225.530} & Canadá: 27.030 & Canadá: 140.310 \\
& & Ontário: 13.610 & Ontário: 105.035 \\
& & Toronto: 10.225 & Toronto: 73.740 \\
\hline \multirow{2}{*}{$2016^{1}$} & \multirow{2}{*}{237.000} & Canadá: 29.315 & Canadá: 139.450 \\
& & Ontário: 14.710 & Ontário: 103.025 \\
& & Toronto: 10.620 & Toronto: 71.045 \\
\hline
\end{tabular}

Também há registro de residentes oriundos de outros estados nacionais lusófonos. Esse encontro de falantes de português ocorre em espaço socioeconômico e sociopolítico particularmente interessante pela sua superdiversidade (VERTOVEC, 2007), ainda mais pelo fato de o Canadá ser um Estado oficialmente multicultural já há algumas décadas (MCALL, 1990).

No que denominou, seguindo Pierre Bourdieu, "mercado português/lusófono de Toronto", Silva (2013, p. 170) identificou múltiplas "tensões entre, por exemplo, identidades locais, nacionais e transnacionais, entre uniformidade e diversidade, e entre as línguas padrões e as variantes regionais" (p. 169), "entre ideologias de monolinguismo e a realidade da complexidade multilingue" (p. 169), "entre diferentes maneiras de ser e de falar português" (p. 170), "entre os dois grupos [...] parceiros no mesmo mercado étnico" (p. 190). Note-se que, nessa tensão formulada no final de seu texto, Silva referese a portugueses e luso-descendentes com origem em Portugal continental ou nos Açores, que estima serem "quase 70\% - principalmente das ilhas de São Miguel e da Terceira" (p. 174). Apontando que "a presença mais recente de outros lusófonos vindos de excolônias portuguesas como Brasil, Angola e Moçambique complica ainda mais o espaço etnolinguístico do mercado português local” (p. 177), Silva não hesita em afirmar, contudo, que, "em geral, brasileiros e africanos são excluídos do discurso dominante de portugalidade que celebra e tenta manter uma só cultura, história e língua de Portugal" (p. 177).

Em artigo em que examina representações midiáticas cômicas que se valem do estereótipo dos portugueses em Toronto como "trabalhadores braçais sem escolarização, mal integrados e sujos que falam mau inglês” (p. 193), Silva (2015b) - ele próprio um luso-canadense - apresenta o cenário nos seguintes termos ${ }^{2}$ :

1 As fontes para os dados do censo de 2016 estão em <http://www12.statcan.gc.ca/censusrecensement/2016/as-sa/98-200-x/2016010/98-200-x2016010-eng.cfm>.,

$<$ http://www12.statcan.gc.ca/census-recensement/2016/dp-pd/hlt-

fst/imm/Table.cfm?Lang $=\mathrm{E} \& \mathrm{~T}=21 \& \mathrm{Geo}=01>$,

$<$ http://www12.statcan.gc.ca/censusrecensement/2016/dp-pd/hlt fst/imm/Table.cfm?Lang=E\&T=21\&Geo=35>

$<$ http://www12.statcan.gc.ca/census-recensement/2016/dp-pd/hlt-

fst $/$ imm/Table.cfm?Lang=E\&T $=22 \& G e o=535>$.

${ }^{2}$ Esta e outras passagens em citação de textos originalmente publicados em inglês aparecem aqui em minha tradução livre, feita para os propósitos da presente discussão.

GARCEZ, Pedro de Moraes. Quem é estudante falante de português em famílias de origem brasileira em Toronto, Canadá? questões de classe. Linguagem em (Dis)curso - LemD, Tubarão, SC, v. 18, n. 3, p. 729-749, set./dez. 2018. 
O mercado português de Toronto também opera dentro de um mercado dominante anglófono maior no Canadá que está dividido em muitas linhas que incluem classe, etnicidade, raça, língua e histórico de migração. O resultado é um mercado sociolinguisticamente estratificado com múltiplas hierarquias. Nesse caso, o português fica posicionado como língua subordinada dado que, entre outras coisas, os seus falantes têm ocupado principalmente empregos de classe trabalhadora desprestigiosos e não têm assumido posições de poder nucleares, nas quais marcas de prestígio e poder são falar inglês padrão "sem sotaque" e alinhar-se com uma cultura canadiana branca anglo-saxã e des-etnicizada. (p. 189-190)

Nesse quadro, Silva sublinha o "estereótipo, que tem larga circulação em Toronto, no Canadá e outras partes, do português operário de construção civil”33 (p. 206). Para além de um grupo étnico minoritarizado, trata-se de um grupo identificado como minoria linguística - possivelmente uma etnoclasse, como veremos mais adiante - marcada por traços de estigma no conjunto do mercado sociolinguístico em que se encontram seus membros e, por extensão, possivelmente os falantes de português em geral.

De particular interesse para os propósitos do que examinamos aqui está o desenvolvimento, ao longo dos anos, de uma categoria nomeada "estudante falante de português" ("Portuguese-speaking student") nos discursos sobre escolarização na cidade. Uma reportagem publicada em revista online sobre o assim chamado "problema de insucesso escolar dos descendentes de portugueses" na cidade resume a questão:

\footnotetext{
Os portugueses de Toronto trouxeram consigo algo mais: desempenho acadêmico miserável. ... são portugueses os que, segundo um relatório de 2006 da Direção Escolar de Toronto (Toronto District School Board), têm o índice mais alto [de evasão escolar] na cidade: 42,5 por cento. ... Isso é quase 20 por cento mais do que a média no município e quase quatro vezes o índice dos estudantes chineses. (ANDREW-GEE, 2012)
}

Esse estado de coisas tem sido objeto de discussão acadêmica (PEREIRA, 2011) e de preocupação detida por parte das duas grandes Direções Escolares da cidade: a Toronto District School Board (doravante TDSB), direção escolar laica; e a Toronto Catholic District School Board (doravante TCDSB), direção escolar católica, que, registre-se, é mantida por recursos públicos.

Desde pelo menos os anos 2000, essas organizações monitoram com atenção os "estudantes falantes de português", tendo sido criados grupos de trabalho, verdadeiras forças-tarefas, para "examinar os padrões associados aos estudantes falantes de português e considerar as opções para apoiar o aumento de seu rendimento" (PRESLEY; BROWN, 2011, p. 1). Relatórios das duas entidades dão conta de número considerável de estudantes da Educação Básica identificados como falantes de português: em 2007, haveria 4.773 estudantes falantes de português na TCDSB e 1.486 na TDSB, a rede pública laica. Em relatório mais recente, Brown, Newton e Tam (2015) informam haver nessa rede "aproximadamente 80 línguas diferentes faladas pelos estudantes da TDSB [...] e 1.426 estudantes falantes de português" (p. 26) em 31 de março de 2014.

\footnotetext{
${ }^{3}$ Outro nicho laboral de trabalhadores portugueses em Toronto é a área de serviços de limpeza, histórica e tradicionalmente identificado como tal conforme atesta Miranda (2009). Gonçalves e Schluter (2017) registram algo semelhante na região metropolitana de Nova Iorque mais recentemente, dando conta também de relações entre falantes de português europeu e brasileiro, e de espanhol.
}

GARCEZ, Pedro de Moraes. Quem é estudante falante de português em famílias de origem brasileira em Toronto, Canadá? questões de classe. Linguagem em (Dis)curso - LemD, Tubarão, SC, v. 18, n. 3, p. 729-749, set./dez. 2018. 
Um dos poucos documentos dessa natureza disponibilizado publicamente pela Direção Escolar Católica, o relatório produzido pelo seu "Comitê Falante de Português" (TCDSB, 2014), informa o seguinte:

\begin{abstract}
Com base nas informações de matrículas para o ano acadêmico 2012-2013, havia 3.946 $(4,3 \%)$ estudantes para os quais os pais relatam ser o português a "língua falada em casa" (fazendo do português a terceira maior língua não inglesa na comunidade do TCDSB). [...] Em 2013-14, o português continua a ser a terceira maior língua não inglesa "falada em casa" na TCDSB. [...] Há 18 escolas primárias na TCDSB onde $10 \%$ ou mais identificaram o português como a língua falada em casa (Trillium, 2012-13). Em nove dessas escolas, mais de um terço identificaram o português como a língua falada em casa. (p. 3)
\end{abstract}

Para além de revelarem que o português é "língua falada em casa" de muitos estudantes das escolas da rede católica de Toronto, esses dados indicam ainda que as famílias que falam português se concentram em nove das 131 escolas primárias da rede.

Muito embora esses documentos tratem de "estudantes falantes de português" em geral, ao menos um dos relatórios explicitamente toma esse rótulo como "a proxy for Luso-Canadians" (PRESLEY; BROWN, 2011, p. 1), isto é, um sinônimo de lusocanadense, ou, como diriam os próprios, luso-canadianos. Assim, embora os dados relatados incluam falantes de português que não são de origem portuguesa, a expressão é usada como termo de referência para estudantes cujas famílias vieram de Portugal continental ou dos Açores. Entretanto, Presley e Brown (2011, p. 1) mencionam de passagem que, em 2010,12\% dos "estudantes falantes de português" eram nascidos no Brasil, e apenas 5\% eram nascidos em Portugal, havendo ainda uma porcentagem não negligenciável de 4\% nascidos em Angola. Brown, Newton e Tam (2015, p. 24), por sua vez, relatam que $21 \%$ dos 1.010 falantes de português registrados no censo escolar de 2011 da TDSB se autoidentificaram como latino-americanos, o que, salvo melhor juízo, quer dizer que se identificaram como brasileiros, dado que a categoria específica (isto é, brasileiro) não constava entre as opções de resposta (nomeadamente, White, Latin American, Mixed e Black). Nos dados do censo escolar de 2014, $13 \%$ dos estudantes falantes de português na rede TDSB eram nascidos na região "América Central/do Sul e México" (BROWN; NEWTON; TAM, 2015, p. 26).

Em suma, fica evidente nos discursos das autoridades educacionais locais que a categoria nomeada como "estudante falante de português" (e latino-americano) inclui os de origem brasileira, sobre os quais pouco se sabe, mas que são tratados indistintamente nesse conjunto de estudantes frequentando escolas de Toronto visto como problemático a ponto de receber atenção especial. Mais que isso, a preocupação das autoridades educacionais, organizada em torno da "língua falada em casa", coloca todos os estudantes brasileiros em associação com os luso-canadenses. Assim, em nossa abordagem inicial para caracterizar quem são esses estudantes e famílias de migrantes brasileiros, interessa saber como se relacionam com os canadenses de origem portuguesa. Conforme proponho aqui, um elemento distintivo entre eles diz respeito a classe social. 
Para além do caráter superdiverso de Toronto, cidade em que metade da população nasceu em outro país (ELLYSON; ANDREW; LEMOINE; CLÉMENT, 2015, p. 4; TASAN-KOK; OZOGUL, 2017, p. 28), o fato de estudantes da Educação Básica serem identificados em categorias com base na língua que (supostamente) falam não chega a surpreender quando se tem em vista a natureza do Estado canadense, oficialmente bilíngue e organizado desde os anos 1970 por políticas oficiais de multiculturalismo (MCALL, 1990). Tais políticas muitas vezes equacionam categorias identitárias com comunidades linguísticas. Essa organização, mais do que celebração ou acolhimento da diversidade, pode ser vista como um conjunto de políticas mais ou menos deliberadas de planejamento a serviço da gestão político-econômica de recursos humanos no capitalismo avançado.

Com efeito, Heller, Bell, Daveluy, McLaughlin e Noël (2016) referem-se aos francófonos no Canadá como uma "etnoclasse", empregando esse termo para nomear uma noção particularmente evidente na economia política canadense: "uma categoria que legitima relações de classe em bases culturais" em referência a "contingentes laborais mobilizáveis, definidos culturalmente, produzidos por formas coloniais e pós-coloniais de capitalismo" (p. 63). Segundo argumentam, "tratar grupos de trabalhadores por categorias culturais, em vez de econômicas, facilita de vários modos a reprodução do processo de produzir diferença e desigualdade" (p. 63): desviando a atenção da base econômica, por um lado, diminui-se a chance de alianças entre grupos culturais em posições semelhantes, enfraquecendo a capacidade de manobra conjunta; por outro lado, reforçada a solidariedade interna ao grupo, deixar de aderir "à comunidade" torna-se um risco para os integrantes, sobretudo os mais frágeis, como, por exemplo, os indocumentados ou os menos qualificados ${ }^{4}$.

A partir disso, proponho a ideia de haver em Toronto uma etnoclasse associada a migrantes portugueses e seus descendentes, tipicamente ocupados em atividades pouco especializadas, como construção civil e serviços de limpeza, que apresentam baixo rendimento escolar e altos índices de evasão da escola secundária, à qual os migrantes brasileiros se associam ou não, conforme se investiga aqui, ao se identificarem, ou serem identificados, como falantes de português, resistindo ou não a essas categorizações. Em particular, no presente trabalho, busco examinar como se manifestam contrastivamente alguns dos estudantes da Educação Básica na cidade e seus pais, situando-os como casos reveladores num conjunto mais amplo de famílias de migrantes brasileiros com quem realizei trabalho de campo durante o ano acadêmico 2015-2016.

Para além de descrever os casos e analisar as construções identitárias dessas famílias e em particular desses estudantes como "falantes de português" nos termos apresentados até aqui, junto-me a um conjunto de autores em Linguística

\footnotetext{
${ }^{4}$ Com vistas aos migrantes brasileiros em Toronto com diferentes status de documentação e qualificação profissional, ver Brasch (2007) e Sega (2013). 
Aplicada/Sociolinguística (BLOCK, 2014, 2017a, 2017b; BATTISTI; LUCAS, 2015; OSHIRO, 2015; RAMPTON, 2010, 2017) que vêm chamando a atenção para a importância de resgatar a centralidade da noção de classe social em nossas reflexões sobre as práticas sociais de linguagem no mundo contemporâneo. Em tempos marcados pela globalização do capital, pelas possibilidades de comunicação e mobilidade, tendo conquistado atenção a questões de reconhecimento ou representação, nos termos de Fraser (1996), talvez tenhamos deixado demasiadamente de lado a atenção a questões de distribuição. Em termos bem mais recentes e próximos, Thurlow (2017, p. 485) alerta para as "eufóricas ideologias pós-classe das formações de riqueza/desigualdade contemporâneas".

O presente trabalho empreende essa aproximação de modo incipiente, sem pretensão de examinar profundamente o conceito de classe social. Ainda assim, mais do que índices de renda ou escolaridade, parto da premissa de que classe social diz respeito à "posição relativa de grandes grupos sociais, definida em relação à ocupação, posse de propriedades e riquezas ou escolhas de estilo de vida" (GIDDENS; SUTTON, 2016, p. 143). Com efeito, os autores dessa definição destacam, entre os aspectos controversos acerca do tema na contemporaneidade, a crítica de sociólogos que viram perda de significado do conceito em função de que a globalização teria produzido "uma divisão do trabalho global na qual as principais desigualdades ocorrem entre um país e outro e não dentro dos Estados-nação" e "classe ficou menos importante para as pessoas dando lugar a gênero, etnia, sexualidade, e afiliação política como fontes de identidade" (p. 146, grifos no original). Assim, quando afirmam que "uma investigação do transnacionalismo força a reflexão crítica sobre a relação entre linguagem e identidade e tem levado a uma série de mudanças de rumo recentes na linguística aplicada e sociocultural", De Fina e Perrino (2013, p. 510) talvez de fato estejam apontando algo que excede os estudos da linguagem. Olhar para os migrantes brasileiros enquanto "estudantes falantes de português" nos cenários escolares do mercado sociolinguístico de Toronto diz algo a esse respeito.

A discussão que empreendo aqui está enquadrada em um entendimento de que ideologias de linguagem são modos de perceber as práticas de linguagem próprias e dos outros, e de agir e julgar as ações dos outros e próprias no que diz respeito às práticas de linguagem. Na definição seminal de Irvine e Gal (2000, p. 35) são conjuntos de "ideias mediante as quais participantes e observadores enquadram seus entendimentos acerca das variedades linguísticas e depois mapeiam esses entendimentos sobre as pessoas, eventos e atividades que lhes são significativas”. Em comentário mais recente, Gal (2016, p. 116) enfatiza que o conceito "recobre uma forma de reflexividade: É metacomunicação, a fala dos participantes sobre a fala, ou as suas reflexões, sinais e pressuposições sobre formas linguística e o uso delas". Aqui, no entanto, não nos deteremos sobre formas específicas, mas apenas em relação às línguas nomeadas do repertório dos participantes, em particular o português e o inglês. Ainda assim, tal como indica Gal (2016, p. 131), resisto "à tentação de presumir que 'o linguista sabe mais' ou de que haja uma 'vista de lugar nenhum' que permitiria aos investigadores determinar quais são as variáveis em vigor numa população"; busco em vez disso "escutar as avaliações dos falantes". 


\section{TRABALHO DE CAMPO EM TORONTO DURANTE O ANO ACADÊMICO 2015-2016}

No trabalho de campo realizado para fins do que apresento aqui, busquei contato com integrantes de grupos de convivência de migrantes brasileiros em Toronto e com agentes educacionais de algum modo vinculados ao atendimento de estudantes falantes de português em Ontário. Inicialmente, uma família de médicos brasileiros residentes em uma cidade próxima me apresentou a colegas em Toronto, que por sua vez recomendaram contato com um grupo de brasileiros, referido aqui pelo pseudônimo "Conversa com Qualidade", que se reúne mensalmente em torno de uma palestra sobre temas relevantes para os frequentadores. Conversei por telefone com as organizadoras, participei de um encontro mensal, depois expus a minha proposta de pesquisa e solicitei auxílio no contato com famílias de estudantes brasileiros. Fui então convidado a proferir palestra e nessa ocasião apresentei à plateia convite para participação na pesquisa. Dessa iniciativa resultaram 16 entrevistas com famílias de origem brasileira, três das quais são tratadas aqui, uma delas mais detidamente. Tendo assegurado um grupo de participantes em potencial e já ambientado no campo, submeti projeto de pesquisa com base nisso a Comitê de Ética em Pesquisa e, assim que recebi o parecer de aprovação ${ }^{5}$, iniciei entrevistas com integrantes desse grupo e suas famílias, o que se estendeu até maio de 2016, paralelamente a outras atividades do trabalho de campo, inclusive participação nos encontros mensais do Conversa com Qualidade.

Para alcançar famílias além do círculo do Conversa com Qualidade, busquei também contatos com especialistas que tivessem atuação relevante com vistas a práticas transnacionais e escolarização multilíngue de crianças brasileiras em Ontário, a saber, educadores atuantes em escolas de Educação Básica em que há concentração de estudantes falantes de português e em particular de estudantes de origem brasileira, educadores atuantes em organizações comunitárias de apoio à escolarização de falantes de português em Toronto, funcionários ou educadores atuantes na administração de redes de ensino mantenedoras de escolas de educação básica em que se identifica a presença de falantes de português, funcionários de representação diplomática, instituto cultural ou associação atuante na promoção da língua portuguesa em Ontário e investigadores acadêmicos estudiosos de questões relativas a práticas transnacionais e escolarização multilíngue de falantes de português em Ontário.

Esses generosos colegas promoveram meu contato com ONGs canadenses que atendem às comunidades de falantes de português na cidade. Numa delas, a diretoraexecutiva sugeriu, entre outros, contato com uma segunda ONG que promove o "Ready, set, learn"6 - programa de reforço escolar para estudantes da educação básica falantes de português e de espanhol, cujas atividades se dão, na sua maior parte, nas manhãs de sábados. Após visitas iniciais às atividades do programa, obtive franco acesso para observação e contato com as famílias de estudantes brasileiros. Acompanhei 10 sessões entre dezembro de 2015 e maio de 2016, e entrevistei sete estudantes e suas famílias alguns nas dependências da escola onde acontecem as sessões do programa ou nas casas

\footnotetext{
${ }^{5}$ Parecer CEP número 1.320.298, de 12/11/2015.

${ }^{6}$ Tomo emprestado de Kwiczala e Kutsyuruba (2012) o pseudônimo para referir ao programa.
} 
das famílias. Seis dessas entrevistas são examinadas aqui, uma delas mais detidamente. Um pai, por sua vez, me apresentou a outro grupo de convivência, de pais (homens) brasileiros que se reúnem sob a organização de uma terceira entidade sem fins lucrativos de apoio a imigrantes falantes de português. Entre dezembro de 2015 e março de 2016, entrevistei duas famílias desse grupo.

Apesar de ciente dos prováveis obstáculos que teria pela frente, desde sempre pretendi estabelecer contato com ao menos uma comunidade escolar em Ontário que atendesse estudantes de origem brasileira para buscar interlocutores entre os alunos, seus pais e os educadores canadenses que com eles interagem direta ou indiretamente, e conhecer as perspectivas desses estudantes situadas no cenário de educação escolar multilíngue propriamente dito. Apresentado a um professor de Educação Básica em uma das grandes redes de ensino do Canadá, ele próprio de origem portuguesa, visitei em novembro de 2015 a escola secundária em que ele atuava. A essa visita se seguiram outras, ocasiões em que pude, ainda que informalmente, observar aulas e conhecer o ambiente escolar em que esse educador atuava, campo que se mostrou promissor para a pesquisa, dada a evidência de um contingente de estudantes (e de educadores) falantes de português em meio a falantes de diversas outras línguas.

Conforme orientado pelos educadores e diretor dessa escola, submeti projeto à Direção Escolar a que pertencia essa escola, que mais tarde eu viria a nomear como Escola Secundária, para pesquisa externa. Recebi autorização para trabalho de campo em até três escolas, com limite, contudo, a entrevistas com no máximo seis docentes e 10 discentes, esses somente "estudantes falantes de português de origem brasileira" e apenas do sétimo ano em diante.

$\mathrm{Na}$ Escola Secundária, registrei entre março e maio entrevistas com sete estudantes, quatro integrantes do corpo docente e um funcionário terceirizado de apoio para acolhimento de estudantes imigrantes estrangeiros. A convivência autorizada na Escola Secundária durante esse período permitiu observação informal para além da realização das entrevistas, inclusive o contato, além dos entrevistados, com diversos outros estudantes de origem brasileira e outros falantes de português que não entrevistei. Realizei entrevistas também em duas escolas primárias dentre as muitas dessa rede onde há ensino de "Português como Língua Internacional". Na Escola Primária 1, entrevistei a professora de Português, mas não havia alunos de origem brasileira identificados no sétimo ano, nem no oitavo. Na Escola Primária 2, em que todas as turmas - do jardim de infância ao oitavo ano - têm aulas de Português diariamente, entrevistei dois alunos de oitavo ano e o professor de Português, que depois disso me convidou para assistir a uma aula de Português com uma turma de sexto ano. As nove entrevistas com estudantes das duas Escolas são tratadas sinoticamente a seguir e uma delas mais detidamente.

Sendo assim, neste trabalho ${ }^{7}$ examino dados gerados apenas com famílias de estudantes que frequentavam (ou, em um caso, havia frequentado) escolas da mesma Direção Escolar, abordados a partir do trabalho de campo nos seguintes sítios:

\footnotetext{
7 Além de estudantes de origem brasileira, seus pais e educadores, entrevistei também membros das representações diplomáticas consulares de países de língua portuguesa em Toronto encarregados de assuntos educacionais, a coordenadora da primeira ONG que eu visitara em novembro, a coordenadora executiva da ONG que promove o programa de reforço escolar "Ready, set, learn", um educador aposentado
} 
- "Conversa com Qualidade" - grupo de migrantes brasileiros que se reúnem mensalmente em torno de um palestrante convidado;

- Uma Escola Secundária (9-12) e duas Escolas Primárias (K-8) de uma grande Direção Escolar;

- "Ready, set, learn" - programa de reforço escolar "para estudantes [...] de origem falante de português e espanhol" (conforme a página de Internet do programa, que não cabe identificar aqui).

Nove dessas entrevistas foram realizadas apenas com os estudantes, os sete da Escola Secundária e os dois na Escola Primária 2. Outras seis entrevistas foram realizadas com estudantes participantes do programa "Ready, set, learn" e seus pais, nas dependências da escola que abrigava o programa ou, no caso de duas dessas famílias, no seu local de residência. As entrevistas com os estudantes e os seus pais frequentadores do Grupo “Conversa com Qualidade” foram realizadas nas residências das famílias. A Figura 1 mostra a localização da maior parte dos locais de residência e escolas num mapa parcial da cidade.

\section{Figura 1 - Localização das escolas e residências dos estudantes e suas famílias ${ }^{8}$}

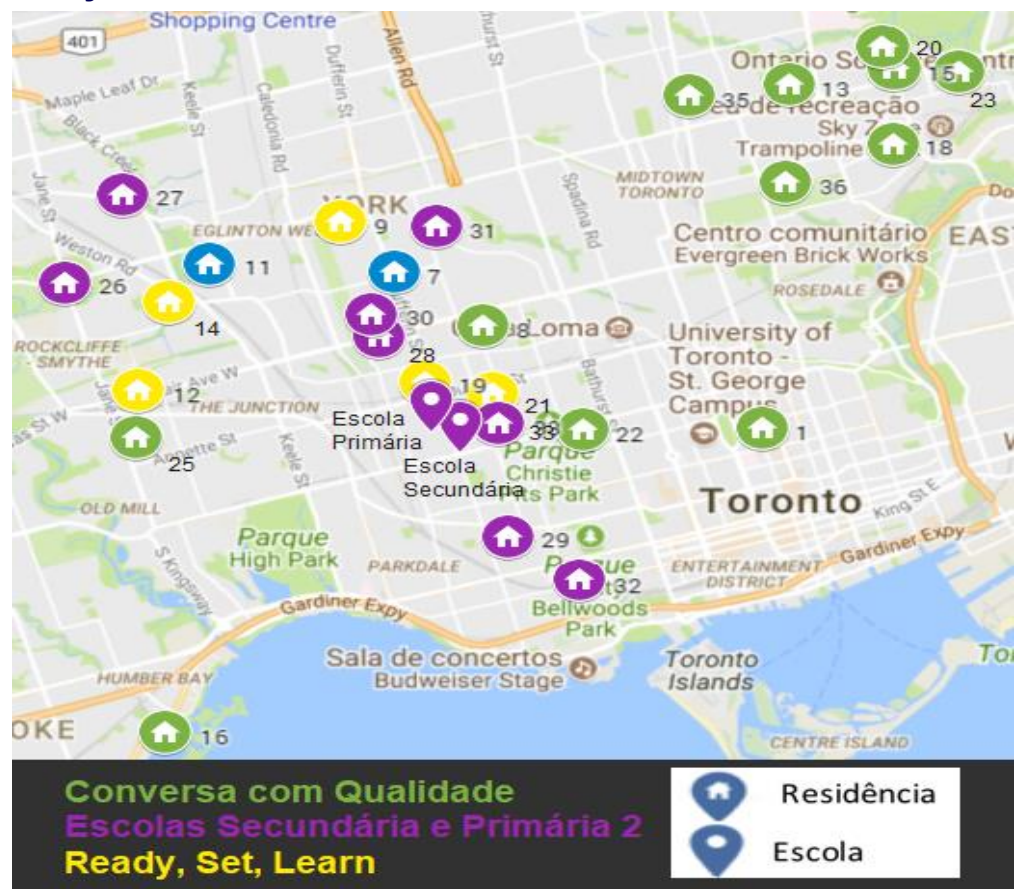

da Direção Escolar que liderou diversas ações educativas voltadas aos falantes de português em Toronto e uma professora de Português da Direção Escolar frequentadora do Conversa com Qualidade, esses dois últimos, eles próprios migrantes brasileiros. Em junho, acompanhei também uma sessão de atividades e entrevistei a coordenadora de uma entidade que promove a prática de português e convívio em cultura brasileira para crianças. Frequentei ainda cultos religiosos e reuniões festivas que congregam famílias brasileiras e percorri diversas áreas da cidade de Toronto onde as atividades observadas tiveram lugar, registrando sempre que possível as evidências de paisagem linguística lusófona.

${ }^{8}$ Alguns poucos entrevistados não figuram nesse mapa. Os dois ícones azuis (7 e 11) indicam entrevistados recrutados por intermédio do Grupo de Pais mencionado acima. 
Como se pode ver na Figura 1, há uma concentração de locais de residência das famílias do grupo Conversa com Qualidade, marcadas em verde, nas áreas à direita, e particularmente no alto à direita, isto é, de áreas a norte e nordeste em relação ao centro histórico da cidade 9 . Já a maior parte dos locais de residências dos estudantes entrevistados nas Escolas e dos estudantes participantes do programa de reforço escolar, bem como as próprias escolas, identificadas em roxo e amarelo, se concentram numa faixa de sul a norte à esquerda, isto é, nas áreas a leste e noroeste do centro histórico de Toronto, justamente as áreas de ocupação inicial e de expansão residencial de migrantes portugueses desde a década de 1950 (TEIXEIRA; MURDIE, 2009, p. 193).

Para uma primeira aproximação aos dados, atentemos, entre as informações sinóticas apresentadas nas Tabelas 2 e 3, para as áreas de ocupação dos pais dos estudantes entrevistados nas Escolas (Tabela 2) em contraste com as dos pais do grupo "Conversa com Qualidade" cujos filhos frequentaram escolas da Direção Escolar ${ }^{10}$ (Tabela 3).

Tabela 2 - Identificação e ocupação dos pais dos estudantes entrevistados na Escola Secundária e na Escola Primária 2 da Direção Escolar

\begin{tabular}{l|l|l|lcl}
\multicolumn{5}{c}{ Escola Secundária e Escola Primária 2} \\
\hline \multicolumn{1}{c|}{ Nome } & Idade & \multicolumn{1}{c}{ Idade de migração } & \multicolumn{2}{c}{ Setor de ocupação dos pais } \\
\hline Isadora & 13 & 4 anos & mãe: acolhimento de migrantes & pai: construção \\
\hline Francis & 12 & nasceu no Canadá & mãe: atividades domésticas & pai: construção \\
\hline Charlene & 19 & 16 anos & mãe: limpeza/administração & padrasto: construção \\
\hline Marco & 18 & nasceu no Canadá & mãe: limpeza (aposentada) & pai: segurança \\
\hline Nathan & 15 & nasceu no Canadá & mãe: limpeza & pai: limpeza \\
\hline Giovanni & 19 & 2 anos & mãe: limpeza & pai: (no Brasil) \\
\hline Elsa & 19 & nasceu no Canadá & mãe: atividades domésticas & pai: construção \\
\hline Anrel & 19 & 17 anos & mãe: (no Brasil) & pai: construção \\
\hline Eddy & 15 & nasceu no Canadá & mãe: limpeza & pai: construção \\
\hline
\end{tabular}

\footnotetext{
${ }^{9}$ Sega (2013, p. 163) também identificou essas áreas como de concentração dos migrantes brasileiros qualificados que estudou.

${ }^{10} \mathrm{O}$ fato de 13 das 16 famílias de migrantes brasileiros frequentadores do grupo Conversa com Qualidade que entrevistei optarem por matricular seus filhos em escolas de outras direções escolares com menor número de migrantes portugueses e luso-descendentes, inclusive em escolas privadas, em si já indica menor proximidade.
} 
Tabela 3 - Identificação e ocupação dos pais dos estudantes entrevistados por abordagem no grupo Conversa com Qualidade que frequentavam (ou havia frequentado) escolas da Direção Escolar

\begin{tabular}{l|l|l|l}
\hline \multicolumn{5}{c}{ Conversa com Qualidade } \\
\hline \multicolumn{1}{c|}{ Nome } & Idade (anos) & Idade de migração (anos) & \multicolumn{1}{c}{ Setor de ocupação dos pais } \\
\hline $\begin{array}{l}\text { Marco } \\
\text { Luzia }\end{array}$ & 15 & 7 & $\begin{array}{l}\text { mãe: odontologia } \\
\text { pai: gestão de investimentos }\end{array}$ \\
\hline $\begin{array}{l}\text { Gilberto } \\
\text { Rebeca }\end{array}$ & 11 & 3 & mãe: pesquisa em universidade \\
pai: música, comércio \\
Marcos & 10 & 4 & mãe: administração \\
Marília & 18 & 11 & pai: tecnologia da informação \\
\hline
\end{tabular}

Observe-se inicialmente que, para além de se concentrarem em áreas residenciais distintas da cidade, conforme revela a Figura 1, as famílias dos dois grupos se diferenciam em termos ocupacionais, sendo que os estudantes da Escola Secundária e da Escola Primária 2 têm pais ocupados em atividades que exigem pouca qualificação profissional, tomadas aqui como indicadores de posição de classe trabalhadora, e os do grupo Conversa com Qualidade, ocupações que pressupõem qualificações profissionais, tomadas aqui como indicadores de posição de classe média. Mais que isso, quase todos os pais dos estudantes entrevistados nas Escolas estão ocupados em atividades das áreas de construção civil e limpeza, típicas do nicho laboral dominado por luso-canadenses, ao passo que os pais dos estudantes de escolas da mesma Direção Escolar contactados por meio do grupo Conversa com Qualidade estão ocupados em atividades de diversas outras áreas.

Disso se depreende que os estudantes do primeiro grupo têm proximidade com a etnoclasse falante de português em Toronto. A isso acrescente-se a informação de que apenas os estudantes agrupados na Tabela 2 convivem com falantes de português não brasileiro no grupo familiar. Nathan tem mãe brasileira e pai português. Eddy diz ter contatos esporádicos com o pai brasileiro, mas a mãe é portuguesa continental, e o padrasto é açoriano; e por isso ele diz falar "all three Portuguese" (os três portugueses): "normal", "brasileiro" e "açoriano". Pude observar Eddy pronunciando expressões chulas em português fluente, mas nossa entrevista foi em inglês. Francis também falou comigo apenas em inglês, mas relatou que a mãe filipina fala português fluentemente com o pai, brasileiro, que, segundo a diretora da Escola Primária 2, não fala inglês. Nas três famílias dos frequentadores do Conversa com Qualidade em foco aqui, por sua vez, ambos os pais são migrantes brasileiros ${ }^{11}$.

${ }^{11}$ No conjunto mais amplos das 16 entrevistas com frequentadores do grupo, há uns poucos pais não brasileiros, nenhum português. 
Para uma maior aproximação, tomemos em contraste o que disseram em entrevista estudantes de uma família em cada um dos dois grupos sobre o valor de falar português (em fundo cinza nas Tabelas 2 e 3). Anrel, 19, cursa um ano extra na Escola Secundária a fim de obter créditos para ingresso no ensino pós-secundário. Quer ser eletricista.

1.

Pedro: mhm. e- e pra conseguir emprego tu acha que pode ajudar ser falante de português? como eletricista?

Anrel: $\quad$ ajuda. porque, trabalhador, de construção, aqui no Canadá, construção é muito forte na área dos portugueses, como eu disse, português gosta muito de trabalhar em construção

Pedro: hmm

Anrel: e como eletricista envolve construção, eu sabendo falar português, me ajudaria a entrar numa empresa portuguesa, vamos dizer assim

Em que pese o propósito de buscar qualificação profissional em estudos póssecundários, Anrel identificou expressamente uma "área dos portugueses", a construção, onde o pai já está, localizando o valor de ser falante de português numa perspectiva local, imediata.

Já Marcos, 18, egresso de uma escola secundária da Direção Escolar, já no primeiro ano de ciências da computação em uma IES local de alta reputação acadêmica, tratou disso quando veio com a irmã, Marília, se juntar aos pais, que já estavam em entrevista comigo: ${ }^{12}$

2 .

Antônio: não só porque é uma língua adicional, que pode ajudá-los no mercado de trabalho no futuro, empresas que precisam de falantes de português para interagir com:: parceiros no Brasil e essas coisas todas mas também para manter contato com a família

Marcos: agora (.) que eu estou entrando no mercado de trabalho então eu acho que é:: coisa boa saber outra língua. então eu quero continuar falando português, mas eu não quero (.) ter que fazer nenhuma aula de português no futuro, então eu espero que eu consiga continuar falando português

Marília: ajuda muito tipo a encontrar um trabalho se você fala mais línguas

Note-se aí que não há qualquer menção a falantes de português em Toronto. Por outro lado, os três dão importância a falar línguas, identificando o português como uma língua adicional entre outras, relevante para o mercado de trabalho em geral e para contatos com o Brasil como possível cenário de atuação profissional. Embora Antônio, o pai, mencione também contatos com a família, ele próprio e os filhos estudantes, Marcos em especial, invocam o que Heller e colaboradores (SILVA; HELLER, 2009; HELLER, 2010; HELLER; DUCHÊNE, 2012, 2016) têm identificado como discursos de profit (lucro), no bojo dos quais recursos e repertórios linguísticos são tratados em uma perspectiva de mercantilização da linguagem, isso em contraste com os evocações mais

\footnotetext{
${ }^{12}$ Ver convenções de transcrição no Apêndice.
} 
tradicionais de pride (orgulho), nos quais recursos e repertórios linguísticos evocam identidades linguísticas e direitos, em geral no bojo de ideologias de linguagem de cunho nacionalista.

Nesses discursos de profit, que observei em diversas entrevistas com os integrantes de outras famílias de migrantes brasileiros que participam das reuniões do Conversa com Qualidade que não estão enfocados aqui, o português é destacado como recurso importante na composição do que Urciuoli (2008) chamou de "feixe de habilidades" comunicativas da pessoa capacitada para a competição nos mercados de trabalho globalizados, em que a "facilidade com línguas" é valorizada. Pouco ou nada disso apareceu nas entrevistas com os estudantes dos outros sítios de abordagem em termos de orientação para mobilidades que conectasse português e esferas de atuação não locais (para além da família estendida dos migrantes).

\section{MIGRANTES BRASILEIROS EM TORONTO}

Dessas aproximações iniciais que fiz aos dados, creio ser possível afirmar que os migrantes brasileiros que conheci nessas famílias se distinguem em seus perfis ocupacionais e locais de residência. As famílias dos estudantes da Escola Secundária e da Escola Primária 2 se ocupam em atividades que exigem pouca qualificação e residem em áreas da cidade que, tal como as próprias escolas, concentram luso-canadenses. Já as três famílias de migrantes frequentadores do Conversa com Qualidade cujos filhos frequentavam (ou, em um caso, havia frequentado) escolas da mesma Direção Escolar se ocupam em atividades que exigem qualificação profissional e residem em áreas da cidade que se distanciam daquelas em que se concentram os luso-canadenses. Mais que isso, da amostra de entrevistas em cada perfil sobre o que disseram sobre o valor de falar português, tem-se uma postura distinta em relação a como se percebem como falantes de português. Sobressai na entrevista com Anrel a percepção de um valor local de ser falante de português em associação à etnoclasse luso-canadense e suas atividades laborais mais típicas, ligadas à área da construção civil. Isso contrasta com a ausência de qualquer percepção ou associação desse tipo entre os integrantes da família de Marcos, em que ser falante de português em Toronto é ter uma língua a mais no portfólio necessário para sucesso no "mercado de trabalho", cujo horizonte se estende para além da cidade.

\section{QUINCY, UMA "ESTUDANTE FALANTE DE PORTUGUÊS" QUE PREFERE NÃO FALAR PORTUGUÊS}

Se Anrel parece ser um estudante falante de português diferente de Marcos e Marília, também é verdade que se assemelham pelo fato de que todos efetivamente falam português confortável e abundantemente. Para uma última aproximação possível no espaço deste artigo, faço ainda um recorte detalhado em uma estudante de $10^{\circ}$ ano em escola secundária da mesma Direção Escolar, participante do programa de reforço escolar para estudantes falantes de português "Ready, set, learn", portanto claramente identificada como tal, que, no entanto, não se identifica confortavelmente assim. 
Demorei a localizar Quincy durante as sessões de sábado de manhã do "Ready, set, learn", mesmo estando seu nome na lista dos estudantes de origem brasileira que recebi da organização do programa. Fiz questão de procurá-la, afinal, porque era das poucas que estavam no ensino secundário. Quando a abordei, ela foi reticente, dizendo que não falava português muito bem. Trocamos para inglês, alternamos as línguas, mas ela continuou manifestando pouca disposição para gastar tempo comigo. Ainda assim, aceitou levar o meu convite aos pais. Na semana seguinte, esbarrou comigo e me disse que tinha perdido o papel onde eu indicava dados para contato e, para minha surpresa, voluntariamente me passou o número de telefone do pai. Quando liguei, fui surpreendido pelo português fluente, mas com sotaque, de Alan, 48, motorista de empresa privada de entrega de encomendas. Nascido no Brasil, havia crescido em família de migrantes brasileiros nos EUA, que mais tarde retornaram para a cidade de origem no interior de São Paulo, onde o jovem Alan encontrou Marlisete, 41, a mãe de Quincy, que à época trabalhava em escritório de contabilidade de um supermercado até migrarem para Toronto, onde Quincy chegou com dois anos de idade, 13 anos antes do nosso encontro. Marlisete, também estudante, fazia pouco mais de um ano havia retomado os estudos para concluir a Educação Básica num programa canadense de educação de jovens e adultos. Os dois irmãos de Quincy, Samuel (10) e Maryah (7), nasceram no Canadá e naquele momento frequentavam o $5^{\circ}$ ano e o $2^{\circ}$ ano da escola primária, respectivamente, em duas escolas primárias distintas, ambas da Direção Escolar. Na escola de Sam, Português é componente curricular diário; na escola de Maryah, é oferecido no contraturno. Segundo relato dos pais, contudo, nenhum dos dois fala português.

A família relatou na entrevista um histórico de contato intenso com outros falantes de português na cidade, principalmente à época em que viviam no coração da região de grande concentração de luso-canadenses, quando participavam de muitas atividades da comunidade religiosa da qual eram membros, onde Alan inclusive ensinava inglês para migrantes recém-chegados. Na nova morada, segunda casa própria da família em Toronto, a igreja mais próxima atende a uma congregação majoritariamente falante de espanhol, e as atividades de estudo e trabalho da família foram apontadas como razão para a diminuição da frequência.

Conforme dados dos Censos do Canadá de 2011 e 2016 disponibilizados no portal de internet da Prefeitura da Cidade de Toronto ${ }^{13}$ apresentados na Tabela 4, no âmbito da unidade censitária (neighbourhood) onde está a casa da família Quincy, quase um quarto das unidades habitacionais tem sido considerado de baixa renda. Nos dados definitivos de 2011, a Renda Mediana do Domicílio Após Dedução de Impostos ficou abaixo do índice geral da cidade, e apenas $5 \%$ das unidades habitacionais ficaram na faixa mais alta de renda. Ali o português tem sido a língua mais citada tanto como "home language", isto é, "a língua falada mais frequentemente em casa ou rotineiramente em casa", quanto como "mother tongue", isto é, a primeira língua aprendida em casa durante a infância e ainda compreendida à ocasião do recenseamento ${ }^{14}$.

13 Disponível em: <https://www.toronto.ca/city-government/data-research-maps/neighbourhoodscommunities/neighbourhood-profiles/>.

${ }^{14}$ Esses índices são semelhantes para a vizinhança de Anrel, onde encontramos, respectivamente em 2011 e 2016, mother tongue português 9,3/6,1\% - inglês 51/54\%; home language português 8,2/5,2\% - inglês

GARCEZ, Pedro de Moraes. Quem é estudante falante de português em famílias de origem brasileira em Toronto, Canadá? questões de classe. Linguagem em (Dis)curso - LemD, Tubarão, SC, v. 18, n. 3, p. 729-749, set./dez. 2018. 
Tabela 4 - Dados demográficos de renda e línguas faladas na vizinhança de Quincy

\begin{tabular}{crr}
\hline & \multicolumn{2}{c}{ Censo do Canadá } \\
\cline { 2 - 3 } & $\mathbf{2 0 1 1}$ & 2016 (preliminar) \\
\hline Renda Mediana do Domicílio Após Dedução de Impostos (anual, em CAD \$) & 46,154 & não disponível \\
Mediana para Toronto (em CAD \$) & 52,149 & \\
Unidades habitacionais de baixa renda & $22 \%$ & $22,8 \%$ \\
Média para Toronto & $19 \%$ & \\
Unidades habitacionais na faixa de renda mais alta (>CAD \$ 125.000) & $5 \%$ & não comparável* \\
Mother tongue & & $12,8 \%$ \\
português & $11,4 \%$ & $49,0 \%$ \\
inglês & $48,0 \%$ & $8,0 \%$ \\
Home language & & $67,0 \%$ \\
português & $6,9 \%$ & $64,0 \%$ \\
inglês & &
\end{tabular}

* As faixas e valores são diferentes nos dois relatórios-fonte.

Ao caminhar pela vizinhança antes da entrevista, tive oportunidade de observar as casas de quarteirão da residência da família de Quincy. Ali, como é comum em áreas de Toronto conhecidas pela expressão "corredor da Avenida X", eixo de expansão da ocupação de migrantes portugueses, havia farta evidência, exposta publicamente nas fachadas, de cultura material identificando a ocupação de luso-canadenses: bandeiras de Portugal e dos Açores, azulejos com imagens de entidades de devoção identificados em português ("Anjo da Guarda") ou indicando o sobrenome da família como é comum nos Açores ("Novo"). Dentro dos carros estacionados, era possível ver objetos identificando as cores de Portugal e distintivos de clubes de futebol portugueses; nas placas anunciando propriedades à venda, corretores de sobrenomes portugueses ("Carlos O. Ferreira"). Na entrevista, Marlisete mencionou contato cotidiano com a vizinhança de origem portuguesa.

Assim, todos os membros da família tinham oportunidade para usar português. Vale notar que Quincy frequenta uma escola secundária da Direção Escolar identificada como entre as que mais concentram "estudantes falantes de português", a tal ponto de ser local de reunião dos comitês e de realização de atividades comunitárias e eventos que discutem e apoiam esses estudantes. Ainda assim, durante a entrevista, Marlisete comentou que o filho, Sam, "não fala português; não se interessa não", acrescentando que "a Quincy fala comigo [em português] porque ela acha que eu ó não sei direito inglês". Arrematou esses comentários avaliando que "as crianças que tão aqui que os pais é brasileiro não quer saber de falar português. deve ser a escola". Interessantemente, Alan discordou, responsabilizando os pais: "Perdendo o português, você tá perdendo a sua origem." De toda sorte, Quincy reiterou que, com o pai e os irmãos, só fala inglês.

Durante a entrevista, Quincy falou português com esforço notável, às vezes atribuindo ao mau português incompreensões comuns a qualquer interlocução oral e que a meu ver pouco tinham a ver com falta de capacidade de expressão na língua de

69/72\%. Já na vizinhança de Marcos e Marília, não há registro de falantes de português, por não ser uma das 10 línguas mais faladas na unidade censitária.

GARCEZ, Pedro de Moraes. Quem é estudante falante de português em famílias de origem brasileira em Toronto, Canadá? questões de classe. Linguagem em (Dis)curso - LemD, Tubarão, SC, v. 18, n. 3, p. 729-749, set./dez. 2018. 
interação. Quando pedi uma avaliação da tutoria no programa de reforço escolar para estudantes falantes de português, manifestou satisfação: "Foi bom. Eles ajuda eu... Quando eu não sabe como fazer o dever de escola." Quando perguntei sobre falar português, disse querer aprender mais, mas foi vaga quando insisti em querer saber detalhes: poderia servir em visitas ao Brasil, nada mais. Quando indaguei sobre planos futuros, contudo, foi eloquente e precisa, disse já ter decidido estudar Medicina e especificou as opções: "quero ir pro University of Toronto, Seneca College, Humber, yeah". Comecei a formular meu entendimento disso, "então daqui a 10 anos...", e Quincy logo completou a frase: "eu já sou médica".

Essa manifestação de planos para estudos pós-secundários exigentes com vistas à formação profissional altamente especializada ${ }^{15}$ pôs em perspectiva o que Quincy disse sobre ser falante de português e mais ainda sobre ser estudante falante de português em Toronto. Quincy havia dito que, não fosse pela mãe, o português já teria desaparecido da vida dela, é língua só de casa, e em casa, como tínhamos visto, só com a mãe ela fala português. "Família!", ela me disse, com a fonética dos is enunciada em /I/. Perguntei, então:

3.

$$
\begin{array}{ll}
\text { Pedro: } & \text { e- lá fora, não interessa muito? aqui } \\
& (0,5) \\
\text { Pedro: } & {[\text { em Toronto] }} \\
\text { Quincy: } & {[\text { n::] não:: }} \\
\text { Pedro: } & \text { não? } \\
& (1,4) \\
\text { Quincy: } & \text { q- t- todo mundo fala INGLÊS não= } \\
\text { Pedro: } & =[\text { mhm=] } \\
\text { Quincy: } & =[\text { por que] eu vou mis:turar o português? }
\end{array}
$$

Depois perguntei:

4.

Pedro: os teus filhos vão falar português?

Quincy: eu não acho.

A essa altura, Marlisete comentou que o português ia estar na vida da Quincy só enquanto ela própria, Marlisete, estivesse viva. Percebi então que o português, para Quincy, é língua materna, no sentido mais estrito.

Crucial para os nossos propósitos aqui, contudo, foi a passagem da entrevista em que Quincy tratou do que se passa na escola e particularmente em decisivas aulas de Matemática, em geral a principal razão para recurso dos "estudantes falantes de português" ao programa de reforço escolar, do qual Quincy era das poucas estudantes secundaristas:

\footnotetext{
15 No Canadá, como nos Estados Unidos, a formação médica requer curso de graduação com ênfases específicas que conduza a um curso de pós-graduação até a titulação e o credenciamento.
} 
5.

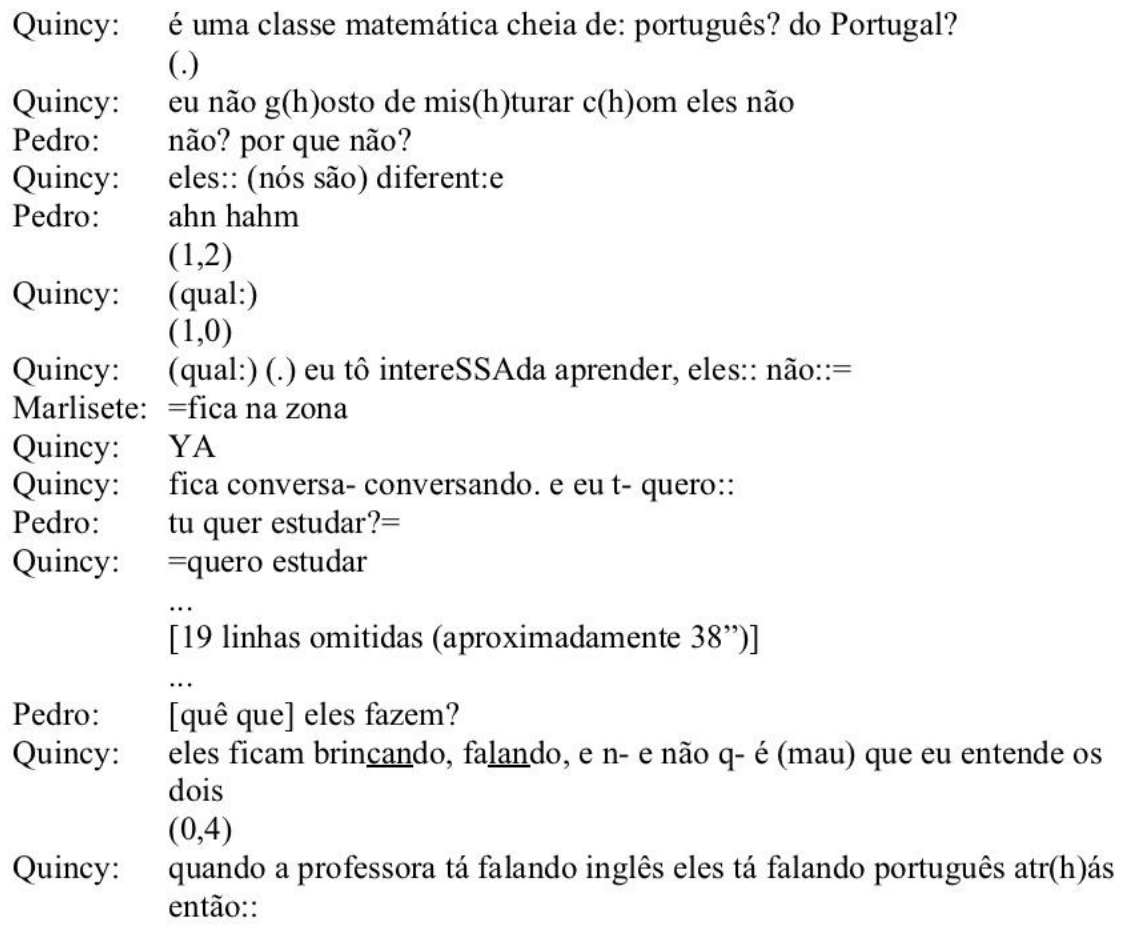

Para além da expressa diferenciação em relação aos colegas falantes de português, chamo a atenção para a distinção que Quincy faz em relação a eles [“(eles:: (nós são) diferent:e"], não por serem "do Portugal", mas porque "eu tô intereSSAda aprender, eles:: não::".

Em síntese, Quincy me fez considerar que ser falante de português pode ser um estigma para estudantes como ela, já que ser associada à etnoclasse pode comprometer as oportunidades acadêmicas necessárias para o acesso à educação superior e pósgraduação, e assim as ambições de carreira em Medicina. Dito de outro modo, dado que ela é linguajada como "estudante falante de português", talvez seja mais vantajoso para Quincy deixar de ser falante de português.

\section{MIGRANTES BRASILEIROS EM TORONTO: CONCLUSÕES PROVISÓRIAS}

O que pude apresentar aqui faz parte de minha percepção de que os entrevistados de famílias que exercem atividades que exigem menor qualificação residem em áreas de concentração de migrantes portugueses, se aproximam da etnoclasse, vendo a língua como meio de obter recursos junto a outros falantes de português em Toronto. Os de famílias que exercem atividades que exigem maior qualificação residem em áreas distantes da concentração de migrantes portugueses, distanciam-se da etnoclasse e apresentam também discursos que associam saber português - uma língua adicional que a vida lhes conferiu - a qualificação pessoal com vistas à competição no mercado de trabalho globalizado que valoriza o multilinguismo e a vantagens de mobilidade. Os "estudantes falantes de português" vinculados à etnoclasse mas que têm ambições acadêmicas exigentes, como creio que Quincy nos mostra, podem ter razões para quererem deixar de ser "falantes de português". 
Nessa configuração, de fato os brasileiros "complicam" o mercado português/lusófono de Toronto, não apenas por colocarem mais tensões em relação a lusocanadenses com origens em Portugal continental e nos Açores, mas também e principalmente por não serem todos iguais. Em particular, quanto à preocupação com o rendimento escolar insatisfatório dos "estudantes falantes de português" em Toronto, o que venho de demonstrar com base no que observei e ouvi aponta para estudantes de origem brasileira com perfil semelhante ao da etnoclasse trabalhadora "luso-canadense", e outros de perfil bem distinto. Nesse sentido, creio que identidades de classe são relevantes para que uns estejam mesmo em integração com a etnoclasse "falante de português" muito mais do que outros, isso guardando relação com atribuições de valor à língua e com perspectivas de manutenção do português entre famílias e estudantes de origem brasileira em Toronto. Interessantemente, essas associações por classe social parecem se destacar na formação de redes pan-lusófonas mais intensas entre os migrantes brasileiros com menor qualificação profissional, muito embora haja elementos de maior investimento na manutenção do português por famílias de migrantes qualificados, o que espero demonstrar em outra ocasião.

De toda sorte, parece evidente que a atenção a elementos de "distribuição" (FRASER, 1996), em especial à "posição relativa [...] em relação à ocupação, [...] ou escolhas de estilo de vida" (GIDDENS; SUTTON, 2016, p. 143) importa para que, em conjunto com a atenção a elementos de reconhecimento, possamos compreender como as pessoas se situam em relação aos repertórios linguísticos próprios e das suas comunidades. Creio que isso importe para compreender um pouco do que são os migrantes de origem brasileira em Toronto e em particular de quem é ou deixa de ser "estudante falante de português" nas escolas dessa cidade evidentemente superdiversa e, talvez, em outros espaços também. Afinal, o que se revelou aqui sobre os perfis de classe social desses migrantes brasileiros contribui para superar a perspectiva das pesquisas sobre superdiversidade na Sociolinguística contemporânea que se pautam, curiosamente, conforme Britain (2016, p. 235), pelo nomadismo ao fetichizarem o migrante internacional e tratá-lo como indiferenciado.

\section{REFERÊNCIAS}

ANDREW-GEE, E. What's eating Little Portugal? Maisonneuve, n. 45, 2012. Disponível em: <https://maisonneuve.org/article/2013/01/7/whats-eating-little-portugal/>. Acesso em: 4 maio 2018. BATTISTI, E.; LUCAS, J. I. P. Class in the social labyrinth of South America. In: SMAKMAN, D.; HEINRICH, P. (Org.). Globalising sociolinguistics: Challenging and expanding theory. Londres/Nova Iorque: Routledge, 2015. p. 153-163.

BLOCK, D. Social class in applied linguistics. Londres: Routledge, 2014.

. Social class language and education research. In: MAY, S.; KING, K.; LAI, Y-J. (Org.). The encyclopedia of language and education, vol. 10, Research methods in language and education. Berlim: Springer, 2017a. p. 159-169.

Social class in migration, identity, and language research. In: CANAGARAJAH, S. (Org.). The Routledge handbook of language and migration. Londres: Routledge, 2017b. p. 133-148.

BRASCH, K. Finding their place in the world: Brazilian migrant identities in an interconnected world. 2007. Tese (Doutorado em Educação) - Ontario Institute for Studies in Education, Universidade de Toronto, Toronto, 2007. 
BRITAIN, D. Sedentarism and nomadism in the sociolinguistics of dialect. In: COUPLAND, N. (Org.), Sociolinguistics: Theoretical debates. Cambridge: Cambridge University Press, 2016. p. 217-241.

DE FINA, A.; PERRINO, S. 'Transnational identities'. Applied Linguistics, v. 34, n. 5, p. 509-515, 2013. ELLYSON, C.; ANDREW, C.; LEMOINE, H.; CLÉMENT, R. Multilingual Toronto: LUCIDE city report. London: LSE Academic Publishing, 2015.

FRASER, N. Social justice in the age of identity politics: Redistribution, recognition, and participation. Conferência na Universidade Stanford. The Tanner Lectures on Human Values. 1996. Disponível em: <https://tannerlectures.utah.edu/_documents/a-to-z/f/Fraser98.pdf>. Acesso em: 5 maio 2018.

GAL, S. Sociolinguistic differentiation. In: COUPLAND, N. (Org.), Sociolinguistics: Theoretical debates. Cambridge: Cambridge University Press, 2016. p. 113-135.

GIDDENS, A.; SUTTON, P. Conceitos essenciais da Sociologia. São Paulo: Editora da UNESP, 2016.

GONÇALVES, K.; SCHLUTER, A. "Please do not leave any notes for the cleaning lady, as many do not speak English fluently': Policy, power, and language brokering in a multilingual workplace. Language Policy, v. 16, n. 3, p. 241-265, 2017.

HELLER, M. Language commodification. Annual Review of Anthropology, v. 39, p. 101-114, 2010.

; DUCHÊNE, A. Pride and profit: Changing discourses of language, capital and nation-state. In: A. DUCHÊNE, A.; HELLER, M. (Org.). Language in late capitalism: Pride and profit. New York: Routledge, 2012. p. 1-21

; DUCHÊNE, A. Treating language as an economic resource: Discourse, data and debate. In: COUPLAND, N. (Org.), Sociolinguistics: Theoretical debates. Cambridge: Cambridge University Press, 2016. p. 139-156.

HELLER, M.; BELL, L. A.; DAVELUY, M.; MCLAUGHLIN, M.; NOËL, H. Sustaining the nation: The making and moving of language and nation. New York: Oxford University Press, 2016.

IRVINE, J. T.; GAL, S. Language ideology and linguistic differentiation. In: Kroskrity P. V., (Org.), Regimes of language: Ideologies, polities, and identities. Santa Fé, EUA: School of American Research Press, 2000. p. 35-84.

KWICZALA, C.; KUTSYURUBA, B. A case study of a community-based tutoring and mentoring program for Portuguese-Canadians students. Portuguese Studies, v. 20, n. 2, p. 79-100, 2012.

MAGAlHÃES, L.; GASTALDO, D.; MARTINELli, G.; HENTGES, A.; DOWBOR, T. P. The many faces of Brazilian immigrants in Ontario. Toronto: Brazil-Angola Community Information Centre, 2009.

MCALL, C. Keeping the Old World going: Multiculturalism and the state in Canada. In: Class, ethnicity, and social inequality. Montreal: McGill-Queen's University Press, 1990. p. 165-178.

MIRANDA. S. Portuguese women's activism in Toronto's building cleaning industry, 1975-1986. In: TEIXEIRA, C.; DA ROSA, V. M. P. (Org.). The Portuguese in Canada: Diasporic challenges and adjustment. (2a. ed.). Toronto: University of Toronto Press, 2009. p. 109-135.

OUSHIRO, L. Interação entre sexo/gênero e classe social no uso variável da concordância verbal. In: FREITAG, R. M. K.; SEVERO, C. G. (Org). Mulheres, linguagem e poder: Estudos de gênero na Sociolinguística brasileira. São Paulo: Blucher, 2015. p. 151-168.

PEREIRA, D. Dropping out or opting out? A qualitative study on how young men of Portuguese ancestry in Toronto perceive masculinity and how this informs educational attainment. 2011. Dissertação

(Mestrado em Educação) - Ontario Institute for Studies in Education, Universidade de Toronto, Toronto, 2011.

PRESLEY, A.; BROWN, R. S. Portuguese-speaking students in the TDSB: An overview. Toronto: Toronto District School Board, 2011. Disponível em: $<$ http://www.tdsb.on.ca/Portals/research/docs/reports/PortuguesespeakingStudentsInTheTDSBOverview.pdf>. Acesso em: 4 maio 2018.

RAMPTON, B. Social class and sociolinguistics. Applied Linguistics Review, v. 1, p. 1-22, 2010.

SEGA, R. F. Projeto Canadá: seletividades e redes de imigrantes brasileiros qualificados em Toronto. 2013. Dissertação (Mestrado em Sociologia) - Programa de Pós-Graduação em Sociologia, Universidade Federal de São Carlos, São Carlos, 2013.

SILVA, E. Tensões sociolinguísticas na comunidade portuguesa/lusófona de Toronto. In: MOITA LOPES, L. P. (Org.). Português no século XXI: ideologias linguísticas. São Paulo: Parábola, 2013, p. 169-191.

GARCEZ, Pedro de Moraes. Quem é estudante falante de português em famílias de origem brasileira em Toronto, Canadá? questões de classe. Linguagem em (Dis)curso - LemD, Tubarão, SC, v. 18, n. 3, p. 729-749, set./dez. 2018. 
Sociolinguistic tensions in the Portuguese/Lusophone community of Toronto, Canada. In: MOITA LOPES, L. P. (Org.). Global Portuguese: Linguistic ideologies in late modernity. Londres: Routledge, 2015a. p. 124-143.

Humor (re)positioning ethnolinguistic ideologies: "You tink is funny?". Language in Society, v. 44, n. 2, p. 187-212, 2015b.

; HELLER, M. From protector to producer: the role of the State in the discursive shift from minority rights to economic development. Language Policy, v. 8, n. 2, p. 95-116, 2009.

STATISTICS CANADA. Immigrant languages in Canada. Census in brief. Language, 2011 Census of Population. Statistics Canada Catalogue no. 98-314-X2011003. Ottawa, 2012.

TASAN-KOK, T.; OZOGUL, S. DIVERCITIES, Living with Urban Diversity: The case of Toronto. Amsterdam and Delft: University of Amsterdam and TU Delft, 2017.

TEIXEIRA, C.; MURDIE, R. A. On the move: The Portuguese in Toronto. In: TEIXEIRA, C.; DA ROSA, V. M. P. (Org). The Portuguese in Canada: Diasporic challenges and adjustment. (2a. ed.). Toronto: University of Toronto Press, 2009. p. 191-208.

TEIXEIRA, C.; DA ROSA, V. M. P. A historical and geographical perspective. In: TEIXEIRA, C.; DA ROSA, V. M. P. (Org). The Portuguese in Canada: Diasporic challenges and adjustment. (2a. ed.). Toronto: University of Toronto Press, 2009. p. 3-17.

THURLOW, C. Queering critical discourse studies or/and performing post-class ideologies. Critical Discourse Studies, v. 13, n. 5, p. 485-514, 2016.

TORONTO CATHOLIC DISTRICT SCHOOL BOARD. Annual report of the Portuguese-speaking committee. Toronto: Toronto Catholic District School Board, 2014. Disponível em:

<https://www.tcdsb.org/Board/TrusteesoftheBoard/Committees/AgendaDocs/Student\%20Achievement\% 20Committee/September\%2011,\%202014/Annual\%20Report\%20on\%20the\%20Portuguese\%20Speaking \%20Committee.pdf >. Acesso em: 4 maio 2018.

URCIUOLI, B. Skills and selves in the new workplace. American Ethnologist, v. 35, n. 2, p. 211-228, 2008 .

VERTOVEC, S. Super-diversity and its implications. Ethnic and Racial Studies, v. 30, n. 6, p. $1024-$ $1054,2007$.

\section{APÊNDICE: CONVENÇÕES DE TRANSCRIÇÃO}

\begin{tabular}{|c|c|c|}
\hline & (ponto final) & entonação descendente \\
\hline & (ponto de interrogação) & entonação ascendente \\
\hline & (vírgula) & entonação de continuidade \\
\hline & (hífen) & marca de corte abrupto \\
\hline & (dois pontos) & prolongamento do som \\
\hline & (sublinhado) & sílaba ou palavra enfatizada \\
\hline & (h's) & riso \\
\hline \multirow[t]{4}{*}{ ] } & (colchetes) & fala simultânea ou sobreposta \\
\hline & (sinais de igual) & elocuções contíguas \\
\hline & (números entre parênteses) & $\begin{array}{l}\text { medida de silêncio (em segundos e décimos de } \\
\text { segundos) }\end{array}$ \\
\hline & (ponto entre parênteses) & micropausa, até $2 / 10$ de segundo \\
\hline ) & (parênteses vazios) & segmento de fala que não pôde ser transcrito \\
\hline vra) & (segmento de fala entre parênteses) & transcrição duvidosa \\
\hline
\end{tabular}

Recebido em: 06/07/18. Aprovado em: 30/09/18.

GARCEZ, Pedro de Moraes. Quem é estudante falante de português em famílias de origem brasileira em Toronto, Canadá? questões de classe. Linguagem em (Dis)curso - LemD, Tubarão, SC, v. 18, n. 3, p. 729-749, set./dez. 2018. 
Title: Children of Brazilian migrant families as Portuguese-speaking students in Toronto: Class matters

Author: Pedro de Moraes Garcez.

Abstract: Children of Brazilian migrant families in Toronto may be indiscriminately identified as Portuguese-speaking students, an expression used by local school districts mainly in reference to Portuguese-Canadians displaying poor academic achievement. Interviews with students of Brazilian origin who attend schools in one same large School District and their families show, however, different socioeconomic profiles, as indicated by the regions of residence and the occupations of parents, and contrasting language ideologies. Samples of the interviewees' discourse in each profile about the value of speaking Portuguese reveal signs that unskilled migrants are closer to the Portuguese-speaking ethnoclass. The choice to avoid speaking Portuguese by a student in this profile with high academic aspirations reinforces the understanding of various perspectives of what it is to be a Portuguese-speaking student in Toronto. The study reinforces the relevance of social class for contemporary language studies, and contributes to a nuanced characterization of international migrant groups.

Keywords: Social class. Globalization. Language ideologies. Migration. Mobility.

Título: ¿Quién es estudiante hablante de portugués en familias de origen brasileña en Toronto, Canadá? Cuestiones de clase

Autor: Pedro de Moraes Garcez.

Resumen: Hijos de familias de migrantes de origen brasileña en Toronto pueden ser vistos como estudiantes hablantes de portugués, expresión usada por administraciones escolares de la ciudad para identificar luso-canadienses marcados por fracaso escolar. Entrevistas con estudiantes de origen brasileña que frecuentan escuelas de una misma Administración Escolar y sus familias muestran, sin embargo, perfiles socioeconómicos distintos, como indicado por las regiones de residencia y ocupaciones de los padres y madres, asociados con ideologías de lenguaje diferentes. Muestras de discurso de entrevistados en cada perfil sobre el valor de hablar portugués revelan indicios de aproximación solo de los migrantes brasileños con menos calificación profesional a la etnicidad de clase hablante de portugués luso-canadiense. El alejamiento del portugués por parte de una estudiante en ese perfil que, sin embargo, posee aspiraciones académicas profundiza el entendimiento de las diferentes perspectivas de lo que es ser estudiante hablante de portugués en Toronto. El estudio aumenta la relevancia de clase social para los estudios de lenguaje en la contemporaneidad. Palabras-clave: Clase social. Globalización. Ideologías de lenguaje. Migración. Movilidad.

AGRADECIMENTOS

Agradeço, pela imensa generosidade, aos participantes da pesquisa, que não cabe identificar, e às diversas pessoas que me conduziram a eles, em especial Ana Thomas, David Pereira, Emanuel da Silva, Hewton Tavares e Maria Tereza Papaleo. Registro meu agradecimento também às estudantes bolsistas de Iniciação Científica Cecília Fischer Dias e Giana Antunes Bess pela assistência e a Alana Fries pelos comentários ao texto. $\mathrm{O}$ trabalho de pesquisa relatado aqui foi realizado com apoio do CNPq mediante bolsa de Pós-Doutorado no Exterior (processo 234543-2014-0) e de Produtividade em Pesquisa (processo 305566-2016-4).

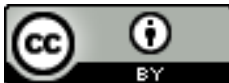

Este texto está licenciado com uma Licença Creative Commons Atribuição 4.0 Internacional.

GARCEZ, Pedro de Moraes. Quem é estudante falante de português em famílias de origem brasileira em Toronto, Canadá? questões de classe. Linguagem em (Dis)curso - LemD, Tubarão, SC, v. 18, n. 3, p. 729-749, set./dez. 2018. 